\title{
Comparison of monoclonal antibodies targeting CD38, SLAMF7 and PD-1/PD-L1 in combination with Bortezomib/ Immunomodulators plus dexamethasone/ prednisone for the treatment of multiple myeloma: an indirect-comparison Meta- analysis of randomised controlled trials
}

Wu Ye, Xia Wu, Xiaoyan Liu, Xue Zheng, Jili Deng and Yuping Gong*(i)

\begin{abstract}
Background: Many clinical trials have assessed the effect and safety of monoclonal antibodies (MAbs) in combination with proteasome inhibitors or immunomodulators plus dexamethasone/prednisone for the treatment of multiple myeloma (MM). The treatment outcomes of comparing different MAbs in combination with the above-mentioned agents remained unclear. We performed the meta-analysis to indirectly compare the effect and safety of MAbs targeting CD38, SLAMF7, and PD-1/PD-L1 in combination with bortezomib/immunomodulators plus dexamethasone/ prednisone for patients with MM.

Methods: We searched thoroughly in the databases for randomised controlled trials (RCTs) in which at least one of the three MAbs were included. We included eleven eligible RCTs with 5367 patients in the meta-analysis. Statistical analysis was carried out using StataMP14 and Indirect Treatment Comparisons software.

Results: We calculated hazard ratios (HRs) for overall survival (OS) and progression-free survival (PFS) and relative risk (RR) for overall response rate, complete response (CR) or better, very good partial response (VGPR) or better, VGPR, partial response, stable disease, and grade 3 or higher adverse events among the three groups. The HRs for PFS of the CD38 group vs SLAMF7 group, CD38 group vs PD-1/PD-L1 group, and SLAMF7 group vs PD-1/PD-L1 group were 0.662 (95\%Cl $0.543-0.806)$, 0.317 (95\%Cl $0.221-0.454)$, and 0.479 (95\%Cl 0.328-0.699), respectively. The HR for OS of the CD38 group vs SLAMF7 group was 0.812 (95\%Cl 0.584-1.127). The RR for CR or better in the CD38 group vs SLAMF7 group was 2.253 (95\%Cl 1.284-3.955). The RR for neutropenia of the CD38 group vs SLAMF7 group was 1.818 (95\%Cl 1.41-2.344).
\end{abstract}

\footnotetext{
* Correspondence: gongyuping2010@aliyun.com; sichuandaxue@scu.edu.cn Department of Hematology, West China Hospital, Sichuan University,

Chengdu, No.37 GuoXue Xiang, Chengdu 610041, Sichuan Province, China
} 
Conclusions: Treatment with the CD38 group had longer PFS and better treatment response than that with the SLAM F7 or PD-1/PD-L1 group. In addition, the SLAMF7 group prolonged PFS compared with the PD-1/PD-L1 group and was associated with a lower incidence of grade 3 or higher neutropenia than the CD38 and PD-1/PD-L1 group. In conclusion, MAbs targeting CD38 are the best, followed by those targeting SLAMF7; MAbs targeting PD-1/PD-L1 are the worst when in combination with bortezomib/immunomodulators plus dexamethasone/prednisone for the treatment of MM.

Keywords: Monoclonal antibodies, CD38, SLAMF7, PD-1/PD-L1, Meta-analysis

\section{Background}

Multiple Myeloma (MM) is a malignant plasma cell disease, which is the second most common malignancy in the hematological system. It accounted for $1 \%$ of all reported tumours and $13 \%$ of hematological cancers. There were approximately 9000 newly diagnosed cases per year in Europe [1]. The cluster of differentiation 38 (CD38) protein is a enzyme with multiple functions including degrading nicotinamide adenine dinucleotide (NAD) and regulating cellular NAD homeostasis; it has been discovered that CD38 was a cell surface marker of hematological malignancies such as MM [2]. CD38 was expressed at high levels in MM cells but at low levels in normal blood cells. Monoclonal antibodies (MAbs) targeting CD38 such as daratumumab approved by the FDA have been applied in the treatment of MM [3]. SLAMF7, also known as CD319, CS1, and CRACC, was high-expressed in MM cells and regarded as a target for specific anti-tumour immune responses [4-6]. The MAbs targeting the surface SLAMF7 glycoprotein of MM cells such as elotuzumab improved the prognosis of MM patients when administered in combination with proteasome inhibitors or

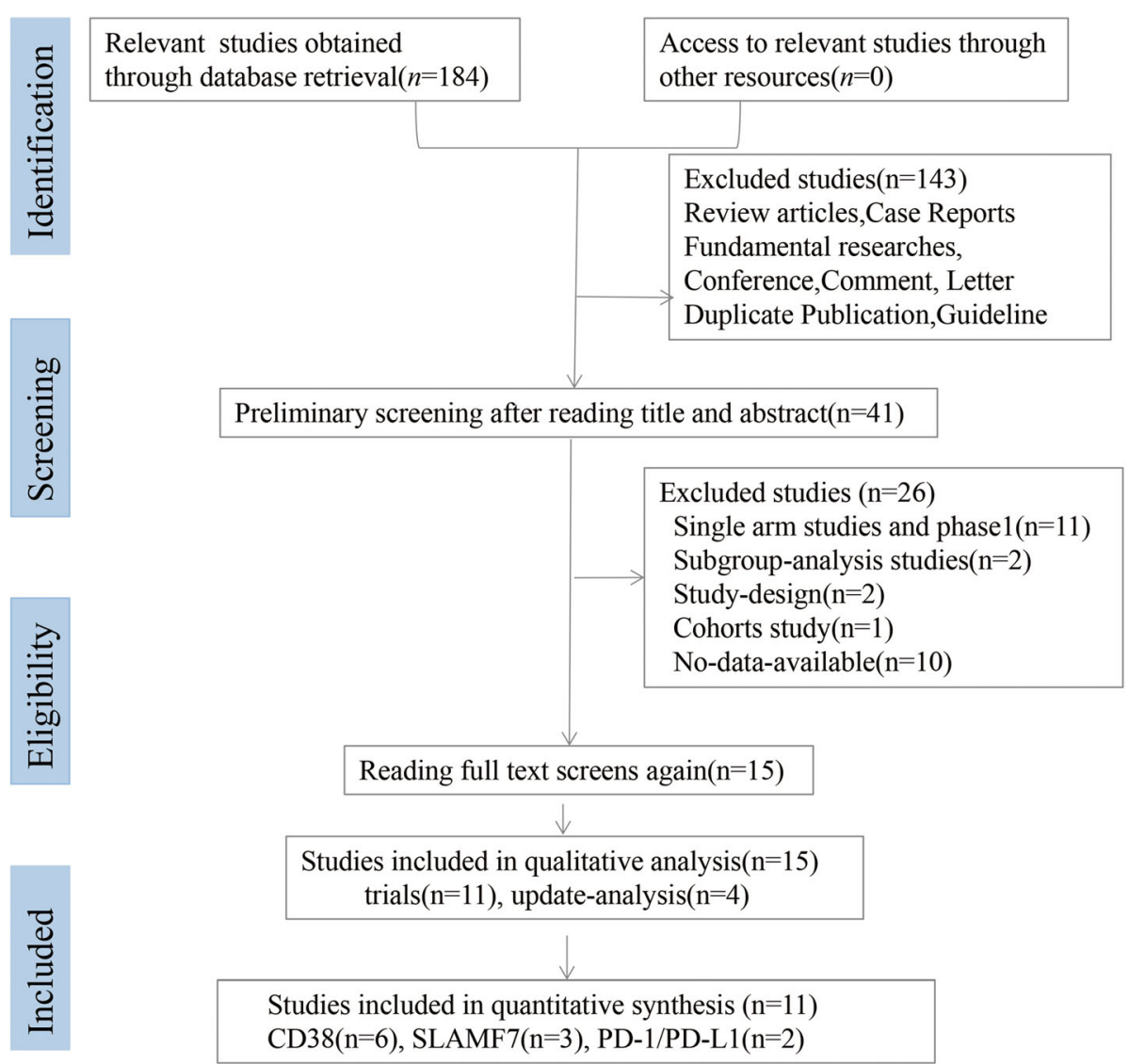

Fig. 1 The screening process of randomised controlled trials included in the meta-analysis 
Table 1 Characteristics of the included studies

\begin{tabular}{|c|c|c|c|c|c|c|c|c|}
\hline Study & Phase & $\begin{array}{l}\text { Number of } \\
\text { patient }\end{array}$ & Treatment regimens & $\begin{array}{l}\text { Median } \\
\text { follow-up } \\
\text { Time(M) }\end{array}$ & $\begin{array}{l}\text { Primary } \\
\text { endpoint }\end{array}$ & $\begin{array}{l}\text { Median } \\
\text { PFS(M) }\end{array}$ & PFS rate & $\begin{array}{l}\text { Median } \\
\text { treatment } \\
\text { Time(M) }\end{array}$ \\
\hline $\begin{array}{l}\text { Dimopoulos(2016) } \\
\text { POLLUX } \\
\text { Dimopoulos(2018) } \\
\text { POLLUX }\end{array}$ & III & 569 & $\begin{array}{l}\text { T:daratumumab } 16 \mathrm{mg} / \mathrm{kg} \text { + lenalidomide } 25 \mathrm{mg} \text { + dexamethasone } 40 \mathrm{mg} \\
\text { C:lenalidomide25mg + dexamethasone40mg }\end{array}$ & $\begin{array}{l}\mathrm{T}: 13.5 \\
\mathrm{C}: 13.5 \\
\mathrm{~T}: 25.4 \\
\mathrm{C}: 25.4\end{array}$ & PFS & $\begin{array}{l}T: N \\
C: 18.4 \\
T: N \\
C: 17.5\end{array}$ & $\begin{array}{l}\text { 12 Months } \\
\text { T:83.2\%C: } \\
60.1 \% \\
24 \text { Months } \\
\text { T:68.0\%C: } \\
40.9 \%\end{array}$ & $\begin{array}{l}\mathrm{T}: 24.5 \\
\mathrm{C}: 16.0\end{array}$ \\
\hline $\begin{array}{l}\text { Palumbo(2016) } \\
\text { CASTOR } \\
\text { Palumbo(2018) } \\
\text { CASTOR }\end{array}$ & III & 498 & $\begin{array}{l}\text { T:daratumumab } 16 \mathrm{mg} / \mathrm{kg} \\
\text { +bortezomib1.3 mg/m² }+ \text { dexamethasone } 20 \mathrm{mg} \\
\text { C:bortezomib1.3 mg/m² }+ \text { dexamethasone } 20 \mathrm{mg}\end{array}$ & $\begin{array}{l}T: 7.4 \\
C: 7.4 \\
T: 19.4 \\
C: 19.4\end{array}$ & PFS & $\begin{array}{l}\mathrm{T}: \mathrm{N} \\
\mathrm{C}: 7.2 \\
\mathrm{~T}: 16.7 \\
\mathrm{C}: 7.1\end{array}$ & $\begin{array}{l}12 \text { Months } \\
\text { T:60.7\%C: } \\
26.9 \% \\
\text { 18 Months } \\
\text { T:48\% C: } \\
7.9 \%\end{array}$ & $\begin{array}{l}\mathrm{T}: 13.4 \\
\mathrm{C}: 5.2\end{array}$ \\
\hline $\begin{array}{l}\text { Facon(2019) } \\
\text { NCT02252172 }\end{array}$ & III & 737 & $\begin{array}{l}\text { T:daratumumab } 16 \mathrm{mg} / \mathrm{kg} \text { + lenalidomide } 25 \mathrm{mg} \text { + dexamethasone } 40 \mathrm{mg} \\
\text { C:lenalidomide } 25 \mathrm{mg}+\text { dexamethasone } 40 \mathrm{mg}\end{array}$ & $\begin{array}{l}T: 28 \\
C: 28\end{array}$ & PFS & $\begin{array}{l}\mathrm{T}: \mathrm{N} \\
\mathrm{C}: 31.9\end{array}$ & $\begin{array}{l}30 \text { months } \\
\mathrm{T}: \mathrm{N} \\
\mathrm{C}: \mathrm{N}\end{array}$ & $\begin{array}{l}\mathrm{T}: 25.3 \\
\mathrm{C}: 21.3\end{array}$ \\
\hline $\begin{array}{l}\text { Mateos (2017) } \\
\text { ALCYONE } \\
\text { Maria(2019) } \\
\text { ALCYONE }\end{array}$ & III & 706 & $\begin{array}{l}\text { T:daratumumab } 16 \mathrm{mg} / \mathrm{kg}+\text { bortezomib } 1.3 \mathrm{mg} / \mathrm{m}^{2}+\text { melphalan9mg/ } \\
\mathrm{m}^{2}+\text { prednisone } 60 \mathrm{mg} / \mathrm{m}^{2} \\
\text { C:bortezomib1.3 mg/m² }+ \text { melphalan } 9 \mathrm{mg} / \mathrm{m}^{2}+\text { prednisone } 60 \mathrm{mg} / \mathrm{m}^{2}\end{array}$ & $\begin{array}{l}\mathrm{T}: 16.5 \\
\mathrm{C}: 16.5 \\
\mathrm{~T}: 40.1 \\
\mathrm{C}: 40.1\end{array}$ & PFS & $\begin{array}{l}\mathrm{T}: \mathrm{N} \\
\mathrm{C}: 18.1 \\
\mathrm{~T}: 36.4 \\
\mathrm{C}: 19.3\end{array}$ & $\begin{array}{l}18 \text { months } \\
\text { T: } 71.6 \% \mathrm{C}: \\
50.2 \% \\
36 \text { months } \\
\text { T:50.7\%C: } \\
18.5 \%\end{array}$ & $\begin{array}{l}\mathrm{T}: 14.7 \\
\mathrm{C}: 12\end{array}$ \\
\hline $\begin{array}{l}\text { Michel (2019) } \\
\text { ICARIA-MM }\end{array}$ & III & 307 & $\begin{array}{l}\text { T:isatuximab10 mg } / \mathrm{kg} \text { + pomalidomide } 4 \mathrm{mg} \text { + dexamethasone } 40 \mathrm{mg} \\
\text { C:pomalidomide } 4 \mathrm{mg} \text { + dexamethasone } 40 \mathrm{mg}\end{array}$ & $\begin{array}{l}\mathrm{T}: 11.6 \\
\mathrm{C}: 11.6\end{array}$ & PFS & $\begin{array}{l}\mathrm{T}: 11.5 \\
\mathrm{C}: 6.5\end{array}$ & $\begin{array}{l}\mathrm{T}: \mathrm{N} \\
\mathrm{C}: \mathrm{N}\end{array}$ & $\begin{array}{l}\mathrm{T}: 9.6 \\
\mathrm{C}: 5.6\end{array}$ \\
\hline $\begin{array}{l}\text { Philippe (2019) } \\
\text { CASSIOPEIA }\end{array}$ & III & 1085 & $\begin{array}{l}\text { T:daratumumab } 16 \mathrm{mg} / \mathrm{kg} \text { + bortezomib } 1.3 \mathrm{mg} / \mathrm{m}^{2}+ \\
\text { thalidomide } 100 \mathrm{mg}+\text { dexamethasone } 40 \mathrm{mg} \\
\text { C:bortezomib1.3 } \mathrm{mg} / \mathrm{m}^{2}+\text { thalidomide } 100 \mathrm{mg}+\text { dexamethasone } 40 \mathrm{mg}\end{array}$ & $\begin{array}{l}\mathrm{T}: 18.8 \\
\mathrm{C}: 18.8\end{array}$ & $S C R$ & $\begin{array}{l}T: N \\
C: N\end{array}$ & $\begin{array}{l}\mathrm{T}: \mathrm{N} \\
\mathrm{C}: \mathrm{N}\end{array}$ & $\mathrm{T}: 8.9$ \\
\hline $\begin{array}{l}\text { Mateos(2019) } \\
\text { KEYNOTE-183 }\end{array}$ & III & 249 & $\begin{array}{l}\text { T: pembrolizumab } 200 \mathrm{mg} \\
\text { +pomalidomide } 4 \mathrm{mg}+\text { dexamethasone } 40 \mathrm{mg} \\
\text { C:pomalidomide } 4 \mathrm{mg}+\text { dexamethasone } 40 \mathrm{mg}\end{array}$ & $\begin{array}{l}\mathrm{T}: 8.1 \\
\mathrm{C}: 8.1\end{array}$ & $\begin{array}{l}\text { PFS } \\
\text { OS }\end{array}$ & $\begin{array}{l}\mathrm{T}: 5.6 \\
\mathrm{C}: 8.4\end{array}$ & $\begin{array}{l}6 \text { months } \\
\mathrm{T}: 48 \% \\
\text { C:60\% }\end{array}$ & $\begin{array}{l}\mathrm{T}: 4.1 \\
\mathrm{C}: 4.2\end{array}$ \\
\hline $\begin{array}{l}\text { Usmani(2019) } \\
\text { KEYNOTE-185 }\end{array}$ & III & 301 & $\begin{array}{l}\text { T:pembrolizumab200mg + lenalidomide } 25 \mathrm{mg} \text { + dexamethasone } 40 \mathrm{mg} \\
\text { C:+lenalidomide } 25 \mathrm{mg}+\text { dexamethasone } 40 \mathrm{mg}\end{array}$ & $\begin{array}{l}\mathrm{T}: 6.6 \\
\mathrm{C}: 6.6\end{array}$ & PFS & $\begin{array}{l}T: N \\
C: N\end{array}$ & $\begin{array}{l}6 \text { months } \\
\text { T: } 82 \% \\
\text { C: } 85 \%\end{array}$ & $\begin{array}{l}\mathrm{T}: 4.4 \\
\mathrm{C}: \mathrm{N}\end{array}$ \\
\hline $\begin{array}{l}\text { Andrzej(2016) } \\
\text { NCT01478048 }\end{array}$ & $\|$ & 152 & $\begin{array}{l}\text { T:Elotuzumab10 mg } / \mathrm{kg}+\text { bortezomib } 1.3 \mathrm{mg} / \mathrm{m}^{2}+\text { dexamethasone } 20 \mathrm{mg} \\
\text { C:bortezomib1.3 mg/m² + dexamethasone } 20 \mathrm{mg}\end{array}$ & $\begin{array}{l}\mathrm{T}: 15.9 \\
\mathrm{C}: 11.7\end{array}$ & PFS & $\begin{array}{l}\mathrm{T}: 9.7 \\
\mathrm{C}: 6.9\end{array}$ & $\begin{array}{l}24 \text { months } \\
\text { T:18\% } \\
\text { C:11\% }\end{array}$ & $\begin{array}{l}\mathrm{T}: \mathrm{N} \\
\mathrm{C}: \mathrm{N}\end{array}$ \\
\hline $\begin{array}{l}\text { Meletios(2018) } \\
\text { ELOQUENT-3 }\end{array}$ & $\|$ & 117 & $\begin{array}{l}\text { T:Elotuzumab } 10-20 \mathrm{mg} / \mathrm{kg}+\text { pomalidomide } 4 \mathrm{mg} \\
+ \text { dexamethasone } 40 \mathrm{mg} \\
\text { C:pomalidomide } 4 \mathrm{mg}+\text { dexamethasone } 40 \mathrm{mg}\end{array}$ & $\mathrm{T}: 9.1$ & PFS & $\begin{array}{l}\mathrm{T}: 10.3 \\
\mathrm{C}: 4.7\end{array}$ & $\begin{array}{l}\mathrm{T}: \mathrm{N} \\
\mathrm{C}: \mathrm{N}\end{array}$ & $\begin{array}{l}\mathrm{T}: 8.4 \\
\mathrm{C}: 4.7\end{array}$ \\
\hline $\begin{array}{l}\text { Sagar(2015) } \\
\text { ELOQUENT-2 } \\
\text { Dimopoulos(2018) } \\
\text { ELOQUENT-2 }\end{array}$ & III & 646 & $\begin{array}{l}\text { T:Elotuzumab10mg } / \mathrm{kg} \\
\text { +lenalidomide } 25 \mathrm{mg}+\text { dexamethasone } 40 \mathrm{mg} \\
\text { C:lenalidomide } 25 \mathrm{mg}+\text { dexamethasone } 40 \mathrm{mg}\end{array}$ & $\begin{array}{l}\mathrm{T}: 24.5 \\
\mathrm{C}: 24.5 \\
\mathrm{~T}: 46 \\
\mathrm{C}: 48\end{array}$ & $\begin{array}{l}\text { PFS } \\
\text { ORR }\end{array}$ & $\begin{array}{l}\text { T: } 19.4 \\
\text { C:14.9 } \\
\text { T:N } \\
\text { C:N }\end{array}$ & $\begin{array}{l}12 \text { months } \\
\text { T:68\%C: } \\
57 \% \\
24 \text { months } \\
\text { T:41\%C: } \\
27 \% \\
48 \text { months } \\
\text { T:21\%C: } \\
14 \%\end{array}$ & $\begin{array}{l}\mathrm{T}: 19 \\
\mathrm{C}: 14\end{array}$ \\
\hline
\end{tabular}

Abbreviations: PFS progression-free survival, ORR overall response rate, SCR stringent complete response, $N$ not available/reached, $T$ trail, $C$ control, $M$ month

Table 2 Quality assessment of the included studies according to Cochrane collaboration's tool for assessing risk of bias

\begin{tabular}{|c|c|c|c|c|c|c|}
\hline Included studies & $\begin{array}{l}\text { Randomized } \\
\text { methods }\end{array}$ & Blind methods & Allocation concealment & Incomplete outcome data & $\begin{array}{l}\text { Selective } \\
\text { reporting }\end{array}$ & $\begin{array}{l}\text { Other } \\
\text { biases }\end{array}$ \\
\hline POLLUXX & Low risk & Unclear & Unclear & Low risk & Unclear & Unclear \\
\hline CASTOR & Low risk & Unclear & Unclear & Low risk & Unclear & Unclear \\
\hline NCT02252172 & Low risk & Unclear & Unclear & Low risk & Unclear & Unclear \\
\hline ALCYONE & Low risk & High risk & Unclear & Low risk & Unclear & Unclear \\
\hline ICARIA - MM & Low risk & High risk & Unclear & Low risk & Unclear & Unclear \\
\hline CASSIOPEIA & Low risk & High risk & Unclear & Low risk & Unclear & Unclear \\
\hline KEYNOTE-183 & Low risk & High risk & Unclear & High risk & Unclear & Unclear \\
\hline KEYNOTE-185 & Low risk & High risk & Unclear & High risk & Unclear & Unclear \\
\hline NCT01478048 & Low risk & High risk & Unclear & Low risk & Unclear & Unclear \\
\hline ELOQUENT-3 & Low risk & Unclear & Unclear & Low risk & Unclear & Unclear \\
\hline ELOQUENT-2 & Low risk & Unclear & Unclear & Low risk & Unclear & Unclear \\
\hline
\end{tabular}


a

\begin{tabular}{|c|c|c|c|}
\hline \multicolumn{2}{|l|}{ Study } & \multirow[b]{2}{*}{$\mathrm{HR}(95 \% \mathrm{Cl})$} & \multirow{2}{*}{$\begin{array}{l}\% \\
\text { Weight }\end{array}$} \\
\hline ID & & & \\
\hline \multicolumn{4}{|l|}{ Daratumumab+Relapsed or refractory } \\
\hline Dimopoulos (2018) & & $0.41(0.31,0.53)$ & 56.36 \\
\hline Palumbo (2016) & $\rightarrow$ & $0.39(0.28,0.53)$ & 43.64 \\
\hline Subtotal $(I-$ squared $=0.0 \%, p=0.814$ ) & & $0.40(0.32,0.48)$ & 100.00 \\
\hline \multicolumn{4}{|l|}{ Isatuximab+Relapsed or refractory } \\
\hline Michel (2019) & & $0.60(0.44,0.81)$ & 100.00 \\
\hline Subtotal $(\mathrm{I}-$ squared $=. \%, \mathrm{p}=)$. & & $0.60(0.41,0.78)$ & 100.00 \\
\hline \multicolumn{4}{|l|}{ Daratumumab+Untreated } \\
\hline Facon (2019) & & $0.56(0.43,0.73)$ & 20.44 \\
\hline Maria (2019) & $\rightarrow$ & $0.42(0.34,0.51)$ & 63.65 \\
\hline Philippe (2019) & & $0.47(0.33,0.67)$ & 15.91 \\
\hline Subtotal $(I-$ squared $=21.9 \%, p=0.278)$ & & $0.46(0.39,0.52)$ & 100.00 \\
\hline \multicolumn{4}{|l|}{ Heterogeneity between groups: $p=0.154$} \\
\hline Overall (I-squared $=21.4 \%, p=0.273$ ) & \langle & $0.45(0.40,0.50)$ & . \\
\hline-.81 & & s1 & \\
\hline
\end{tabular}

b

Study

ID
HR $(95 \% \mathrm{Cl}) \quad$ Weight

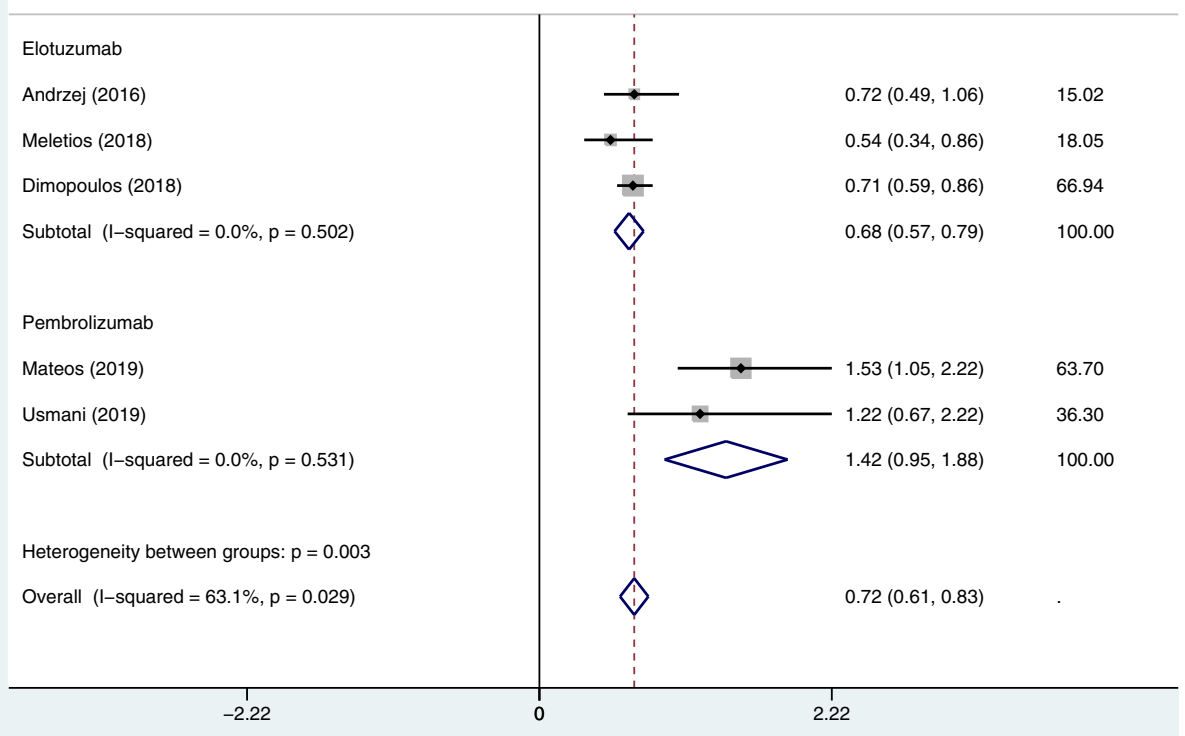

Fig. 2 (See legend on next page.) 
(See figure on previous page.)

Fig. 2 a. Forest plots of the pooled HRs for the PFS of the patients with relapsed or refractory MM or untreated MM in the MAbs targeting CD38 (including daratumumab, and isatuximab) group versus control group. The HR $<1$ favours the MAb group. The size of the blocks or diamonds represents the weight of the fixed effects model in the meta-analysis. $\mathbf{b}$ Forest plots of the pooled HRs for the PFS of the patients with MM in the MAbs targeting SLAMF7 (including elotuzumab) and PD-1/PD-L1 (including pembrolizumab) groups versus their corresponding control groups. The HR $<1$ favours the MAb group. The size of the blocks or diamonds represents the weight of the fixed effects model in the meta-analysis

immunomodulators [7, 8]. Apart from CD38 and SLAM F7, the programmed cell death protein 1 (PD-1) and its ligand - programmed cell death ligand 1 (PD-L1) also played a significant role in MM cells. The pathway of PD1/PD-L1 was a significant negative modulator of immune responses, which was over up-regulated in MM cells and was one of the critical factors for immune escape of tumour cells [9]. In the treatment of MM patients, the MAbs targeting PD-1/PD-L1, including pembrolizumab, durvalumab and nivolumab, had been reported [10]; unfortunately, anti-PD-1/PD-L1 antibodies had poor therapeutic effect as a single agent [11].

Many clinical trials have assessed the effect and safety of using MAbs in combination with proteasome inhibitors or immunomodulators plus dexamethasone/ prednisone in the treatment of MM. However, there has been no clinical study comparing the effects of different MAbs directed to different targets in combination with the above-mentioned drugs. Thus, we performed a meta-analysis to indirectly compare the effect and safety of the MAbs targeting CD38, SLAM F7, and PD-1/PD-L1 in combination with bortezomib/ immunomodulators plus dexamethasone/prednisone in patients with MM.

\section{Methods}

We performed this meta-analysis based on PRISMA statements, and the protocol was registered with PROSPERO, number CRD42020171456.

\section{Study inclusion and exclusion criteria}

Inclusion criteria: 1 . The three experimental groups were the MAbs targeting CD38, SLAMF7, or PD-1/PD-L1 in combination with bortezomib/immunomodulators plus dexamethasone/prednisone; the control groups were blank, placebo, or conventional agents. 2. Participants were patients diagnosed with MM. 3. Study outcomes included survival outcomes, treatment responses, and common adverse events. 4. Studies must be randomised controlled trials (RCTs).

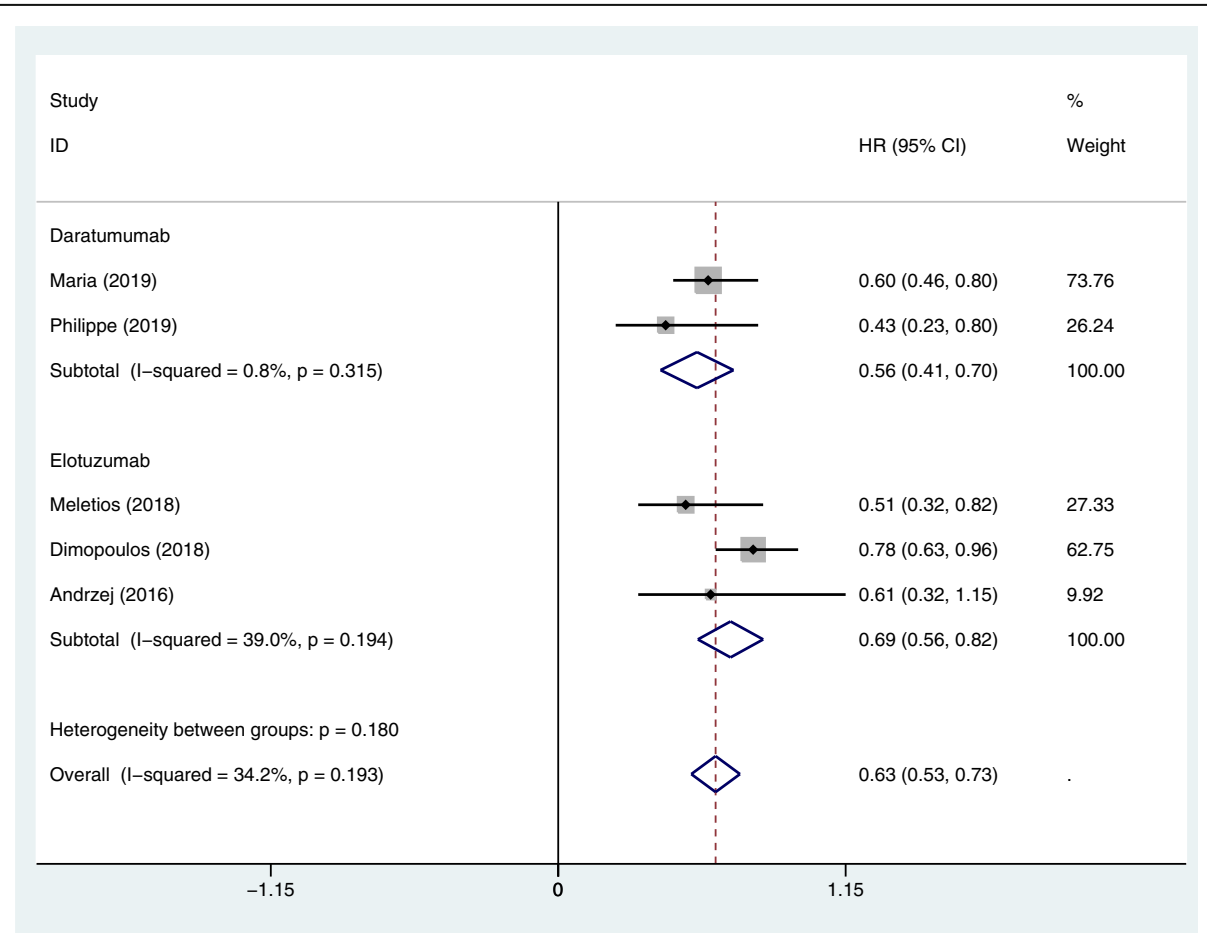

Fig. 3 Forest plots of the pooled HRs for the OS of the patients with MM in the MAbs targeting CD38 (including daratumumab) and SLAMF7 (including elotuzumab) groups versus their corresponding control groups. The HR $<1$ favours the MAb group. The size of the blocks or diamonds represents the weight of the fixed effects model in the meta-analysis 


\section{a}

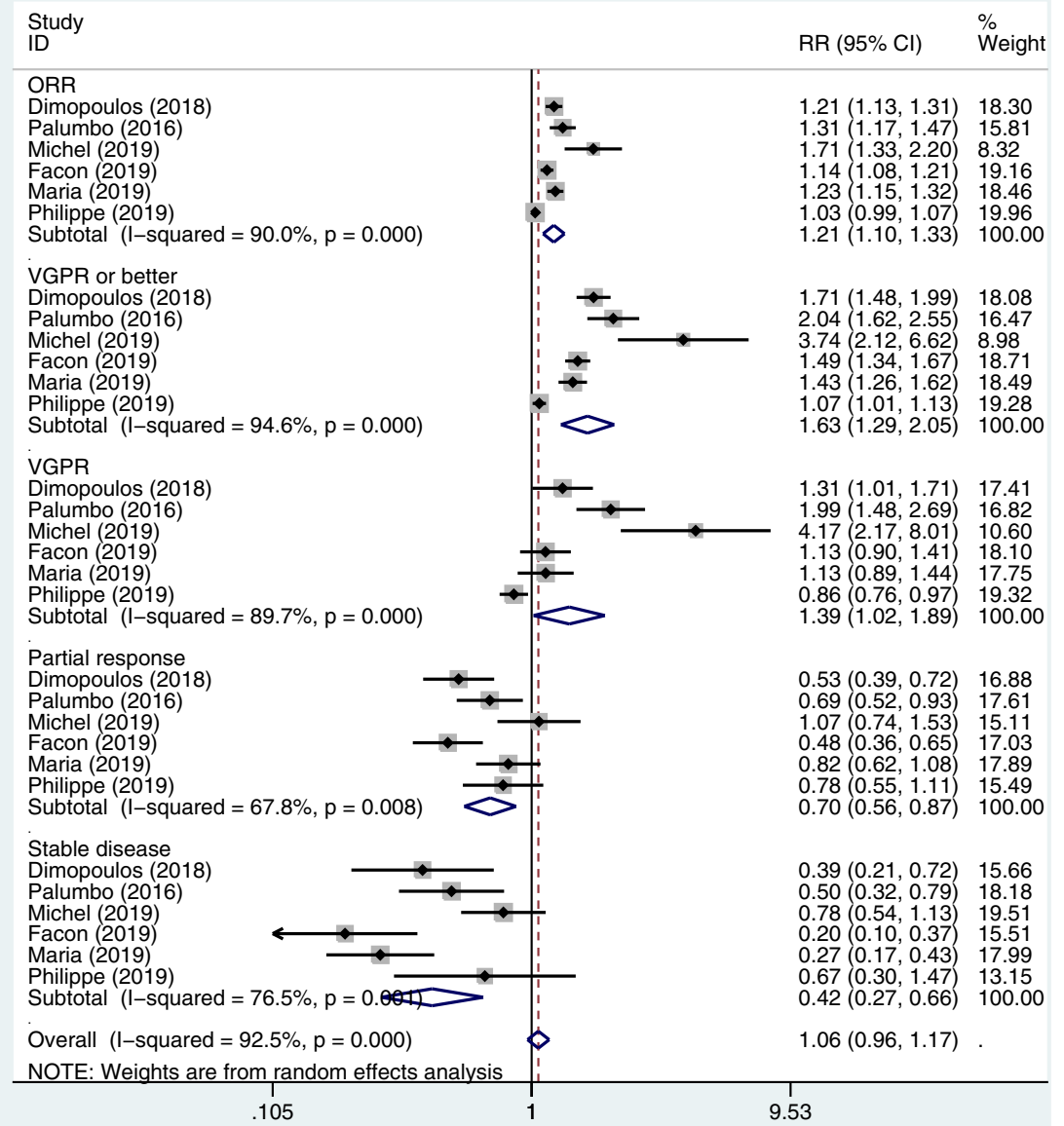

b

Study

ID
$\%$

RR $(95 \% \mathrm{Cl}) \quad$ Weight

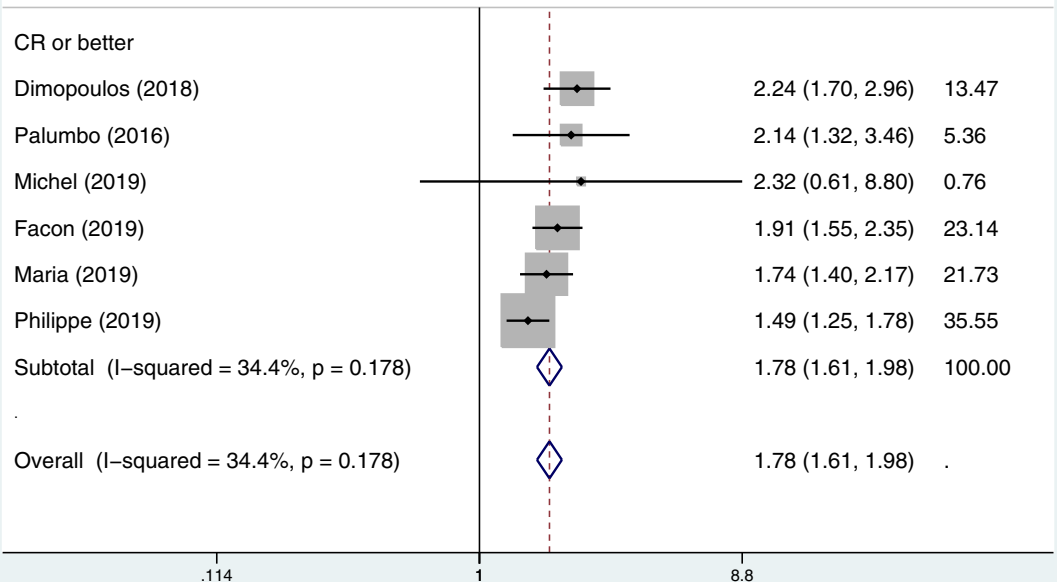

Fig. 4 (See legend on next page.) 
(See figure on previous page.)

Fig. 4 a. Forest plots of the pooled RRs for the ORR, VGPR or better, VGPR, partial response, and stable disease of the patients with MM in the MAbs targeting CD38 group versus control group. The RR > 1 favours the MAb group. The size of the blocks or diamonds represents the weight of the random effects model in the meta-analysis. $\mathbf{b}$ Forest plots of the pooled RR for the complete response or better of the patients with MM in the MAbs targeting CD38 group versus control group. The RR > 1 favours the MAb group. The size of the blocks or diamonds represents the weight of the fixed effects model in the meta-analysis

Exclusion criteria: 1 . The same study was published repeatedly. 2. The studies had incomplete results and we obtained no supplementary data after contacting the author. 3. The studies involved basic research and animal experimental research. 4. Studies had an insufficient follow-up time or more than $20 \%$ of the patients included in the study were lost to follow-up.

\section{Search strategy and screening}

Systematic studies searches were performed using PubMed, Embase, Medline, Web of Science, Cochrane Library and Chinese Biomedical Database (before 26 Feb 2020). The retrieval terms and methods were as following: 1\#: "Monoclonal Antibodies" OR "CD38" OR "PD-1/PD-L1" OR "SLAMF7" OR "CD319" OR "CS1" OR "19A" OR "CRACC" OR "Daratumumab" OR "Isatuximab" OR "MOR202" OR "TAK-079" OR "Pembrolizumab" OR "Nivolumab" OR "Elotuzumab", 2\#: "Bortezomib" OR" Immunomodulatory" OR "Lenalidomide" OR "Pomalidomide" OR "Thalidomide", 3\#: "Dexamethasone" OR "Prednisone", 4\#: "Multiple Myeloma", 5\#: 1\#AND2\#AND3\#AND4\#. Two authors independently reviewed the titles and abstracts to screen potentially eligible studies; subsequently, two authors reviewed the full text to screen qualified articles independently. Disagreements between authors were solved by consensus or consultation with a third author.

\section{Critical appraisal of the included studies}

According to 'Cochrane collaboration's tool for assessing the risk of bias', the evaluation contents include the following aspects: 1. Blind methods; 2. Randomized methods; 3 . Allocation concealment; 4. Incomplete outcomes; 5 . Selective reporting; 6 . Other biases. Two authors assessed the quality of the studies independently.

\section{Data extraction}

All data from the included studies were extracted independently by two authors. We extracted the information including the number of patients, the experimental and control groups, follow-up time, survival outcomes, treatment responses of patients, and common hematological and non-hematological adverse events.

In the meta-analysis, progression-free survival (PFS) was the primary endpoint [12]; the secondary endpoints included overall survival (OS), overall response rate (ORR), complete response (CR) or better, very good partial response (VGPR) or better, VGPR, partial response (PR), stable disease (SD), and grade 3 or higher common hematological and non-hematological adverse events.

\section{Statistical analysis}

To estimate the pooled hazard ratios (HRs) for survival outcomes or relative risk (RR) for the treatment response and the incidence of adverse events, we conducted a conventional meta-analysis by using the StataMP14 software. Statistical heterogeneity was assessed by $\mathrm{I}^{2}$ statistic. If $\mathrm{I}^{2}$ was more than $50 \%$, we considered that there was distinct heterogeneity among studies. We selected the random-effects model to estimate the effect values when distinct heterogeneity existed, otherwise the fixed-effects model was selected [13]. HRs with their corresponding 95\% confidence intervals (CI) for OS and PFS were utilized to compare the prognostic survival; RR with 95\% CI was utilized to compare the treatment responses of patients and the incidence of adverse events [12].

Finally, we used the Indirect Treatment Comparisons (ITC) software to compare HR or RR generated as described above.

\section{Results}

Screening results and characteristics of the included studies

We retrieved a total of 184 articles from PubMed, Embase, Medline, Web of Science, Cochrane Library and Chinese Biomedical Database. The process of study selection was shown in Fig. 1. Preliminary screening after reading titles and abstracts, excluding review articles, basic research articles, case reports, conferences, comments, letters, guidelines, and duplicate publications, resulted in the selection of 41 studies. After reading the full-text of studies again and following the exclusion of single-arm and phase 1, subgroup-analysis, study-design, cohorts, and no-data-available studies, we obtained 15 articles totally that included 11 RCTs and 4 updateanalysis studies [14-17]. Finally, 11 RCTs with 5367 patients were included in quantitative synthesis. Six RCTs [18-23] investigated the effect and safety of the MAbs targeting CD38 (including daratumumab, and isatuxi$\mathrm{mab})$, three [24-26] investigated the effect and safety of 
a

Study

ID
RR $(95 \% \mathrm{Cl}) \quad$ Weight

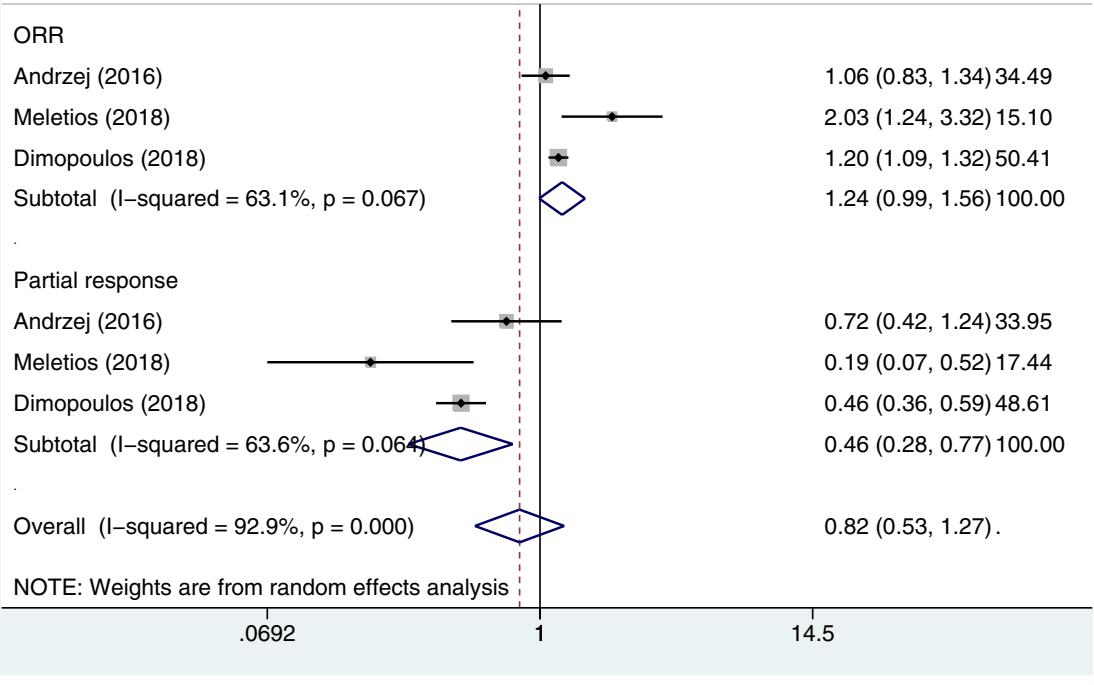

b

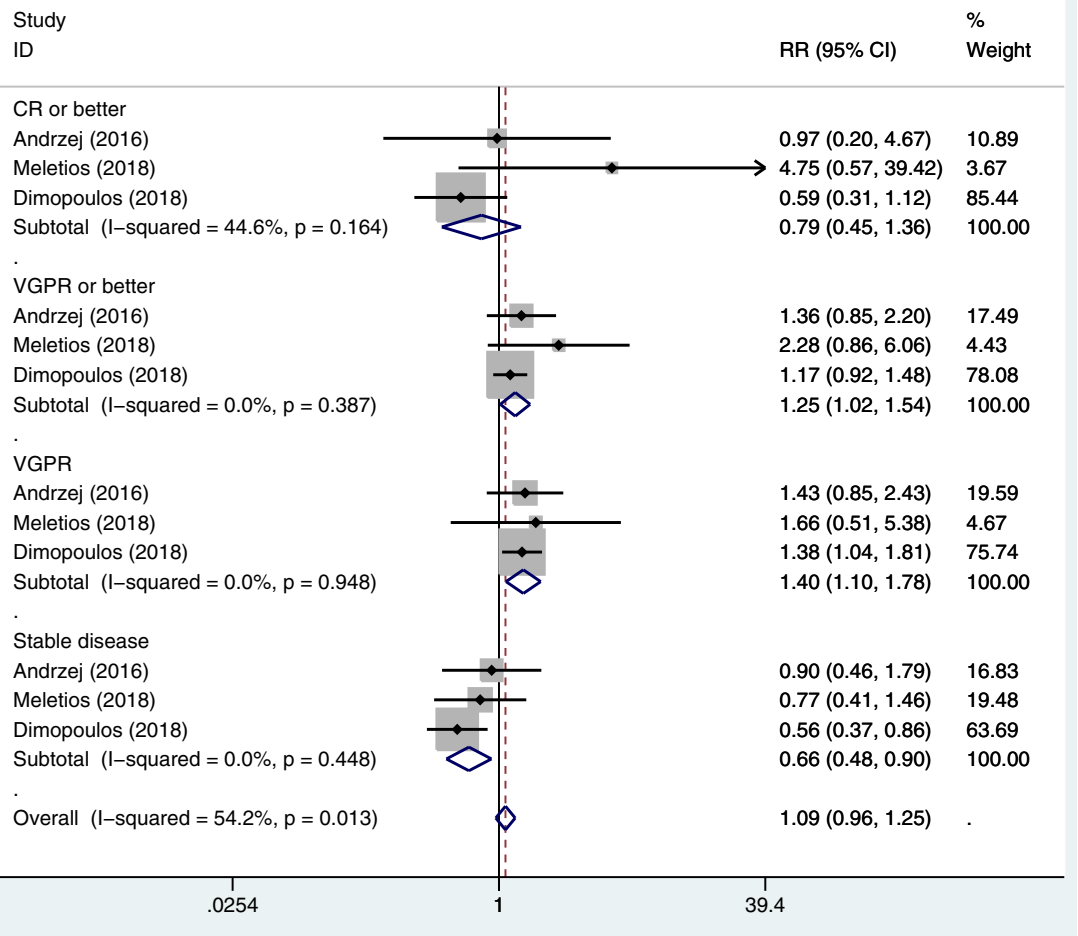

Fig. 5 (See legend on next page.) 
(See figure on previous page.)

Fig. 5 a. Forest plots of the pooled RRs for the ORR and partial response of the patients with MM in the MAbs targeting SLAMF7 group versus control group. The RR> 1 favours the MAb group. The size of the blocks or diamonds represents the weight of the random effects model in the meta-analysis. b Forest plots of the pooled RRs for the CR or better,VGPR or better, VGPR, and stable disease of the patients with MM in the MAbs targeting SLAMF7 group versus control group. The RR > 1 favours the MAb group. The size of the blocks or diamonds represents the weight of the fixed effects model in the meta-analysis

the MAbs targeting SLAMF7 (including elotuzumab), and two $[27,28]$ investigated the effect and safety of the MAbs targeting PD-1/PD-L1 (including pembrolizu$\mathrm{mab})$. Characteristics of the included studies were presented in Table 1 and characteristics of the patients at baseline were presented in Additional file 1.

According to 'Cochrane collaboration's tool for assessing the risk of bias', we assessed the quality of the included studies, with the result indicating that the quality of all were high; the details of the quality assessment were presented in Table 2.

\section{Progression-free survival}

All of the 11 RCTs provided PFS and HRs [12]. First, we synthesized the pooled HRs of the MAbs targeting CD38, SLAMF7, and PD-1/PD-L1 groups versus their corresponding control groups by StataMP14 software (Fig. 2a, b). The pooled HRs for the PFS of the MAbs targeting CD38, SLAMF7, and PD-1/PD-L1 groups vs their corresponding control groups were 0.45 (95\% CI $0.40-0.50$ ), 0.68 (95\%CI $0.57-0.79$ ), and 1.42 (95\% CI $0.95-1.88)$, respectively. Second, we indirectly calculated the HRs for the PFS of the MAbs targeting CD38 group vs SLAMF7 group, CD38 group vs PD-1/PD-L1 group, and SLAMF7 group vs PD-1/PD-L1 group as 0.662 (95\%CI 0.543-0.806), 0.317 (95\%CI $0.221-0.454)$, and 0.479 (95\%CI 0.328-0.699), respectively. The MAbs targeting CD38 group and SLAMF7 group prolonged PFS compared with their corresponding control groups, and the MAbs targeting CD38 group showed a longer PFS than the SLAMF7 group by indirect comparison. In contrast, the MAbs targeting PD-1/PD-L1 group performed the worst among the three groups. In a subgroup analysis of the MAbs targeting CD38 group, the HR for the PFS of the daratumumab group vs control group was $0.40(95 \% \mathrm{CI} 0.32-0.48)$ as compared to $0.60(95 \% \mathrm{CI}$ $0.41-0.78$ ) of the isatuximab group vs control group, suggesting that the daratumumab group may result in longer PFS than the isatuximab group in patients with relapsed or refractory MM.

\section{Overall survival}

Two RCTs about the MAbs targeting CD38 and three RCTs about the MAbs targeting SLAMF7 provided OS and HR with the pooled HRs being 0.56 (95\%CI $0.41-$ 0.70 ) and 0.69 (95\%CI $0.56-0.82$ ), respectively (Fig. 3). The HR for the OS of the MAbs targeting CD38 group vs the MAbs targeting SLAMF7 group was 0.812 (95\%CI $0.584-1.127$ ) by indirect comparison. There was no significant difference in the OS between the two groups.

\section{ORR, CR or better, VGPR or better, VGPR, PR, SD}

We used the same method as the above-mentioned, the pooled RRs for the ORR, CR or better, VGPR or better, VGPR, PR, and $\mathrm{SD}$ in the MAbs targeting CD38 group vs control group were 1.21 (95\%CI 1.101.33), 1.78 (95\%CI 1.61-1.98), 1.63 (95\%CI 1.29-2.05), 1.39 (95\%CI 1.02-1.89), 0.70 (95\%CI $0.56-0.87)$, and 0.42 (95\%CI 0.27-0.66), respectively (Fig. 4a, b). Further, we conducted subgroup analysis, according to the treatment status (primary or recurrent) and the classification of the antibodies, and found that there was no significant relationship between heterogeneity and the two factors. The pooled RRs for the ORR, CR or better, VGPR or better, VGPR, PR, and SD in the MAbs targeting SLAMF7 group vs control group were 1.24 (95\%CI $0.99-1.56), 0.79$ (95\%CI $0.45-1.36)$, 1.25 (95\%CI 1.02-1.54), 1.40 (95\%CI 1.10-1.78), 0.46 (95\%CI $0.28-0.77$ ), and 0.66 (95\%CI $0.48-0.90)$, respectively (Fig. 5a, b). The pooled RR for the ORR in the MAbs targeting PD-1/PD-L1 group vs control group was 0.97 (95\%CI 0.82-1.13). The RRs for the ORR, CR or better, VGPR or better, VGPR, PR, and $\mathrm{SD}$ in the MAbs targeting CD38 group vs SLAMF7 group were 0.976 (95\%CI $0.763-1.248), 2.253$ (95\%CI 1.284-3.955), $\quad 1.304 \quad$ (95\%CI $0.956-1.778), \quad 0.993$ (95\%CI $0.671-1.468), 1.522$ (95\%CI $0.876-2.642)$, and 0.636 (95\%CI $0.368-1.099)$ by indirect comparison, respectively. The RRs for the ORR in the MAbs targeting CD38 group vs PD-1/PD-L1 group and in the SLAMF7 group vs PD-1/PD-L1 group were 1.247 (95\%CI 1.035-1.503) and 1.278 (95\%CI $0.968-1.688$ ), respectively. As for the treatment response, the MAbs targeting CD38 group was better than the MAbs targeting SLAMF7 group in terms of 'CR or better'. The MAbs targeting PD-1/PD-L1 group had a worse treatment response compared to the MAbs targeting CD38 group and SLAMF7 group.

\section{Grade 3 or higher hematological and non-hematological adverse events}

The pooled RRs for neutropenia, anemia, thrombocytopenia, lymphopenia, pneumonia, diarrhea, and fatigue in the MAbs targeting CD38 group vs 
a

\begin{tabular}{|c|c|c|c|}
\hline \multicolumn{2}{|l|}{$\begin{array}{l}\text { Study } \\
\text { ID }\end{array}$} & \multirow[t]{2}{*}{$\mathrm{RR}(95 \% \mathrm{Cl})$} & $\begin{array}{l}\% \\
\text { Weigh }\end{array}$ \\
\hline Neutropenia & & & \\
\hline Dimopoulos (2018) & + & $1.36(1.13,1.62)$ & 19.01 \\
\hline Palumbo (2016) & & $2.93(1.51,5.65)$ & 5.53 \\
\hline Michel (2019) & $\rightarrow$ & $1.21(1.07,1.37)$ & 21.12 \\
\hline Facon (2019) & & $1.41(1.19,1.68)$ & 19.29 \\
\hline Maria (2019) & & $1.03(0.86,1.24)$ & 18.81 \\
\hline Philippe (2019) & & $1.88(1.47,2.40)$ & 16.24 \\
\hline Subtotal ( $(-$ squared $=78.2 \%, p=0.000$ ) & & $1.40(1.17,1.67)$ & 100.00 \\
\hline \multicolumn{4}{|l|}{ Anemia } \\
\hline Dimopoulos (2018) & & $0.73(0.51,1.04)$ & 20.22 \\
\hline Palumbo (2016) & & $0.95(0.63,1.44)$ & 16.66 \\
\hline Michel (2019) & & $1.13(0.80,1.61)$ & 20.38 \\
\hline Facon (2019) & & $0.60(0.42,0.85)$ & 20.44 \\
\hline Maria (2019) & & $0.80(0.58,1.11)$ & 22.30 \\
\hline Subtotal $(I-$ squared $=45.3 \%, p=0.120)$ & & $0.82(0.66,1.01)$ & 100.00 \\
\hline \multicolumn{4}{|l|}{ Thrombocytopenia } \\
\hline Dimopoulos (2018) & & $0.88(0.59,1.31)$ & 15.89 \\
\hline Palumbo (2016) & $\frac{1}{70}$ & $1.38(1.09,1.73)$ & 24.39 \\
\hline Michel (2019) & & $1.26(0.87,1.83)$ & 17.10 \\
\hline Maria (2019) & & $0.92(0.75,1.12)$ & 26.09 \\
\hline Philippe (2019) & & $1.48(1.01,2.17)$ & 16.53 \\
\hline Subtotal $(I-$ squared $=63.4 \%, p=0.027)$ & & $1.15(0.92,1.43)$ & 100.00 \\
\hline \multicolumn{4}{|l|}{ Lymphopenia } \\
\hline Dimopoulos (2018) & & $1.35(0.63,2.90)$ & 12.97 \\
\hline Palumbo (2016) & & $3.74(1.55,9.02)$ & 10.08 \\
\hline Facon (2019) & & $1.41(0.96,2.08)$ & 34.74 \\
\hline Philippe (2019) & & $1.76(1.28,2.42)$ & 42.21 \\
\hline Subtotal $(I-$ squared $=30.7 \%, p=0.228)$ & & $1.70(1.26,2.29)$ & 100.00 \\
\hline Overall (I-squared $=77.1 \%, p=0.000$ ) & ४ & $1.21(1.06,1.38)$ & 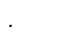 \\
\hline \multicolumn{4}{|l|}{ NOTE: Weights are from random effects analysis } \\
\hline 1 & & & \\
\hline
\end{tabular}

b

Study
ID

Fig. 6 (See legend on next page.) 
(See figure on previous page.)

Fig. 6 a. Forest plots of the pooled RRs for the grade 3 or higher hematological adverse events (including neutropenia, anemia,

thrombocytopenia, and lymphopenia) of the patients with MM in the MAbs targeting CD38 group versus control group. The RR $<1$ favours the MAb group. The size of the blocks or diamonds represents the weight of the random effects model in the meta-analysis. $\mathbf{b}$ Forest plots of the pooled RRs for the grade 3 or higher non-hematological adverse events (including pneumonia, upper respiratory tract infection, diarrhea, and fatigue) of the patients with MM in the MAbs targeting CD38 group versus control group. The RR $<1$ favours the MAb group. The size of the blocks or diamonds represents the weight of the fixed effects model in the meta-analysis

control group were $1.40(95 \% \mathrm{CI} 1.17-1.67), 0.82(95 \% \mathrm{CI}$ 0.66-1.01), 1.15 (95\%CI $0.92-1.43), 1.70$ (95\%CI $1.26-$ 2.29), 1.51 (95\%CI 1.21-1.89), 1.33 (95\%CI 0.92-1.91), and 2.00 (95\%CI 1.33-3.02) (Fig. 6a, b). The pooled RRs for neutropenia, anemia, thrombocytopenia, lymphopenia, pneumonia, diarrhea, and fatigue in the MAbs targeting SLAMF7 group vs control group were 0.77 (95\%CI 0.64-0.92), 0.88 (95\%CI 0.67-1.17), 0.97 (95\%CI $0.73-1.28), 1.63$ (95\%CI 1.43-1.85), 1.32 (95\%CI $0.88-$ 1.98), 1.33 (95\%CI $0.73-2.41$ ), and 1.19 (95\%CI $0.75-$ 1.91), respectively (Fig. 7). The pooled RRs for neutropenia, anemia, pneumonia, diarrhea, and fatigue in the MAbs targeting PD-1/PD-L1 group vs control group were 1.16 (95\%CI 0.97-1.38), 1.45 (95\%CI 0.892.36), 1.14 (95\%CI 0.65-1.99), 2.98 (95\%CI 0.71-12.44), and 0.40 (95\%CI $0.15-1.08$ ), respectively (Fig. 8). The RRs for neutropenia, anemia, thrombocytopenia, lymphopenia, pneumonia, diarrhea, and fatigue in the MAbs targeting CD38 group vs SLAMF7 group were 1.818 (95\%CI 1.41-2.344), 0.932 (95\%CI $0.656-1.323$ ), 1.186 (95\%CI $0.83-1.694), 1.043$ (95\%CI $0.753-1.444), 1.144$ (95\% CI0.72-1.817), 1.00 (95\%CI $0.497-2.014)$, and 1.681 (95\%CI 0.903-3.13), respectively. The RRs for neutropenia, anemia, pneumonia, diarrhea, and fatigue in the MAbs targeting CD38 group vs PD-1/PD-L1 group by indirect comparison were 1.207 (95\%CI 0.94-1.55), 0.566 (95\%CI $0.332-0.963), 1.325$ (95\%CI $0.725-2.419$ ), 0.446 (95\%CI $0.102-1.956)$, and 5.00 (95\%CI $1.717-$ 14.56), respectively. The RRs for neutropenia, anemia, pneumonia, diarrhea, and fatigue in the MAbs targeting SLAMF7 group vs PD-1/PD-L1 group were 0.664 (95\%CI 0.515-0.855), 0.607 (95\%CI 0.346-1.064), 1.158 (95\%CI $0.58-2.311), 0.446$ (95\%CI $0.095-2.105)$, and 2.975 (95\%CI $0.998-8.867)$, respectively. As for the incidence of the adverse events, the MAbs targeting CD38 group exhibited a lower risk of anemia but a higher risk of fatigue than the MAbs targeting PD-1/ PD-L1 group. The MAbs targeting SLAMF7 group had a lower risk of neutropenia than the MAbs targeting PD-1/ PD-L1 and CD38 groups.

The indirect-comparison results of efficacy and safety among the three groups were summarized in Table 3.

\section{Discussion}

MM is an incurable hematological malignancy with various clinical manifestations and outcomes [29]. With the use of new agents such as bortezomib and lenalidomide, the clinical outcomes of MM patients have dramatically improved. Unfortunately, most patients with MM eventually relapsed even after $\mathrm{CR}$, which brings great challenge to the treatment of the disease [12, 30]. The application of MAbs brings new hope for the treatment of MM. CD38 was highly expressed in MM cells but less expressed on normal cells; this makes it a promising target for immunotherapy [29]. The anti-CD38 MAbs, including daratumumab, MOR202, and isatuximab, were well tolerated, and achieved PR or better in about 30\% of patients with $\mathrm{MM}$ as a single agent, and are promising partners in combination therapy $[4,31]$. The SLAMF7 was expressed at a high level on MM and natural killer (NK) cells [8]. The MAbs targeting SLAMF7 such as elotuzumab are able to activate NK cells and enhance antibody-dependent cell-mediated cytotoxicity, making SLAMF7 an attractive target in tumour immunotherapy [4]. The clinical outcomes of patients with MM have been improved by the application of elotuzumab in combination with other agents [7]. In MM, immune disorders have become a significant part of novel therapeutic strategies [10]. As an immune checkpoint receptor, PD-1 regulates the activity of $\mathrm{T}$-cells by interacting with $\mathrm{PD}$ L1 and PD-L2 [32]. Specifically speaking, PD-1 binding with PD-L1 on the surface of MM cells inhibits T cellproliferation and contributes to the immune escape of cancer cells [10]. In the treatment of MM, it seems to be an appropriate approach based on combination therapy on the condition that monotherapy with PD-1/PD-L1 MAbs had yielded unsatisfactory outcomes [33, 34]; the MAbs targeting PD-1/PD-L1 include pembrolizumab, durvalumab, and nivolumab. This meta- analysis compared the effect and safety of the MAbs targeting CD38, SLAMF7, and PD-1/PD-L1 in combination with bortezomib/immunomodulators plus dexamethasone/prednisone in the treatment of MM. As for survival outcomes, the MAbs targeting CD38 group resulted in longer PFS than the MAbs targeting SLAMF7 and PD-1/PD-L1 groups; the MAbs targeting SLAMF7 group produced a longer PFS than the MAbs targeting PD-1/PD-L1 group. Based on these results, we can conclude that the MAbs targeting CD38 group had the best PFS followed by those targeting SLAMF7 group; the MAbs targeting PD1/PD-L1 group was the worst by indirect comparison. As for the treatment responses, the MAbs targeting 


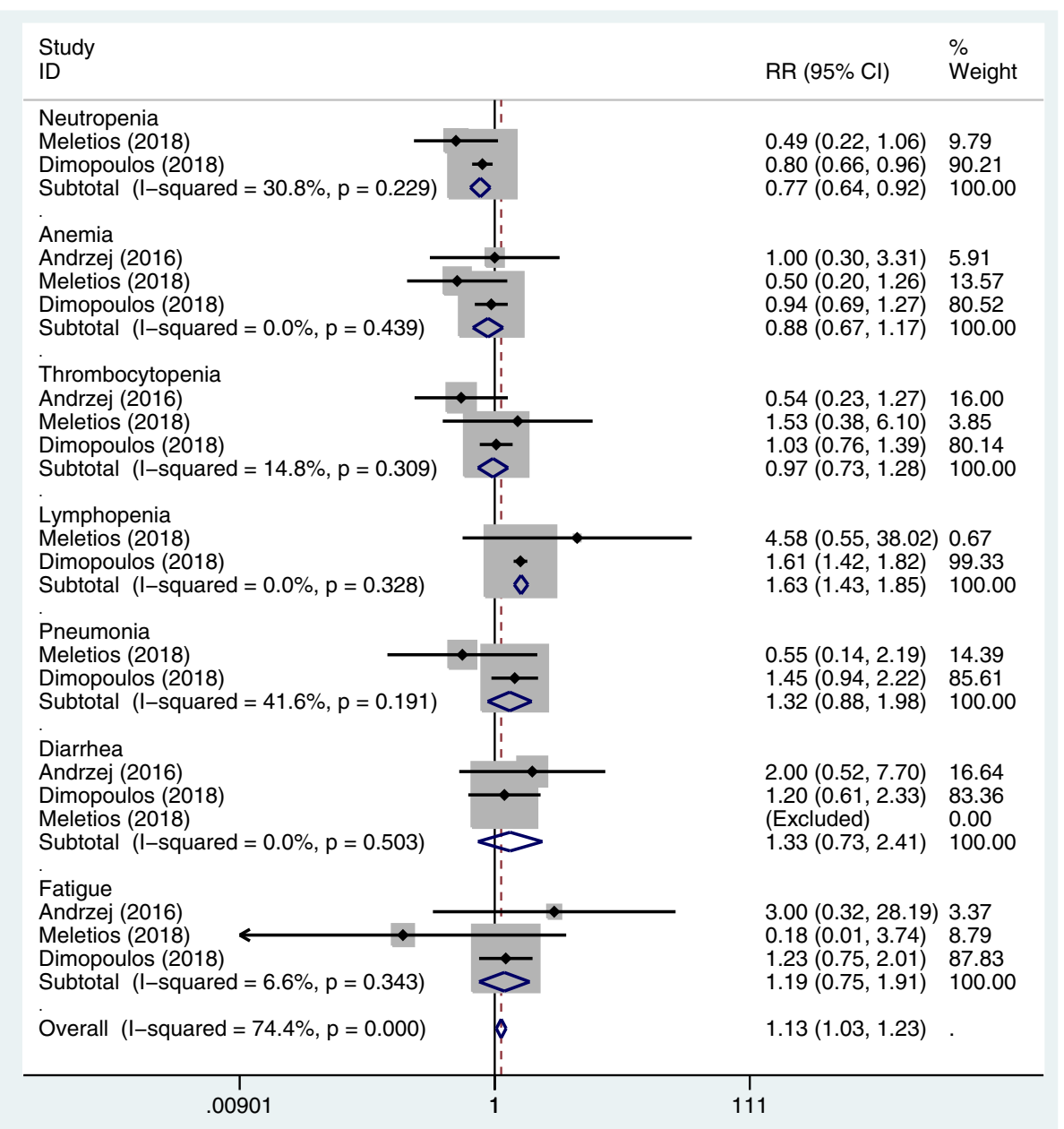

Fig. 7 Forest plots of the pooled RRs for grade 3 or higher hematological (including neutropenia, anemia, thrombocytopenia, and lymphopenia) and non-hematological adverse events (including pneumonia, diarrhea, and fatigue) of the patients with MM in the MAbs targeting SLAMF7 group versus control group. The RR $<1$ favours the MAb group. The size of the blocks or diamonds represents the weight of the fixed effects model in the meta-analysis

CD38 group elicited better treatment responses than the MAbs targeting SLAMF7 group in terms of 'CR or better', with no significant difference between the two with respect to ORR, VGPR or better, VGPR, PR, and SD. As for the incidence of grade 3 or higher hematological and non-hematological adverse events, the MAbs targeting CD38 group was associated with a higher incidence of neutropenia and a similar incidence of anemia, thrombocytopenia, lymphopenia, pneumonia, and diarrhea compared with the MAbs targeting SLAMF7 group. The MAbs targeting PD-1/PD-L1 group had a higher or similar incidence of adverse events (except fatigue) compared with the MAbs targeting CD38 group or SLAMF7 group.

To our knowledge, this is the first meta-analysis comparing the effect and safety of different MAbs in combination with other agents in the treatment of patients with MM. However, this meta-analysis has several limitations. First, the number of included studies testing the MAbs targeting SLAMF7 and PD-1/PDL1 was insufficient, and heterogeneity existed among studies in the pooled RRs for the treatment responses of the MAbs groups vs corresponding controls. Second, the original data for each patient was not available and the abstracted data were from the published studies; meta-analysis based on individual patient data would be more valid for providing more reliable estimates. Third, we did not use sensitivity analysis to evaluate the impact of each study on the stability of the pooled effect by excluding individual studies one at a time because of the limited number of the included studies. Finally, for the same reason, we did not detect publication bias for the meta-analysis by using Egger's and Begg's tests. 


\begin{tabular}{|c|c|c|}
\hline $\begin{array}{l}\text { Study } \\
\text { ID }\end{array}$ & $\mathrm{RR}(95 \% \mathrm{Cl})$ & $\begin{array}{l}\% \\
\text { Weight }\end{array}$ \\
\hline \multicolumn{3}{|l|}{ ORR } \\
\hline Mateos (2019) & $0.85(0.62,1.18)$ & 34.98 \\
\hline Usmani (2019) & $1.03(0.86,1.22)$ & 65.02 \\
\hline Subtotal $(I-$ squared $=2.5 \%, p=0.311)$ & $0.97(0.82,1.13)$ & 100.00 \\
\hline \multicolumn{3}{|l|}{ Disease control } \\
\hline Mateos (2019) & $1.00(0.90,1.11)$ & 45.28 \\
\hline Usmani (2019) & $0.96(0.87,1.07)$ & 54.72 \\
\hline Subtotal (I-squared $=0.0 \%, p=0.592)$ & $0.98(0.91,1.05)$ & 100.00 \\
\hline \multicolumn{3}{|l|}{ Neutropenia } \\
\hline Mateos (2019) & $1.18(0.99,1.40)$ & 83.45 \\
\hline Usmani (2019) & $1.04(0.53,2.02)$ & 16.55 \\
\hline Subtotal $(I-$ squared $=0.0 \%, p=0.697)$ & $1.16(0.97,1.38)$ & 100.00 \\
\hline \multicolumn{3}{|l|}{ Anemia } \\
\hline Mateos (2019) & $1.26(0.69,2.31)$ & 66.27 \\
\hline Usmani (2019) & $1.82(0.80,4.17)$ & 33.73 \\
\hline Subtotal $(I-$ squared $=0.0 \%, p=0.479)$ & $1.45(0.89,2.36)$ & 100.00 \\
\hline \multicolumn{3}{|l|}{ Pneumonia } \\
\hline Mateos (2019) & $1.08(0.56,2.08)$ & 71.07 \\
\hline Usmani (2019) & $1.30(0.46,3.65)$ & 28.93 \\
\hline Subtotal $(I-$ squared $=0.0 \%, p=0.764$ ) & $1.14(0.65,1.99)$ & 100.00 \\
\hline \multicolumn{3}{|l|}{ Diarrhea } \\
\hline \multicolumn{3}{|c|}{$\begin{array}{l}1.01(0.14,7.04) \quad 79.72 \\
10.71(0.60 .191 .89) 20.28\end{array}$} \\
\hline \multirow{2}{*}{\multicolumn{3}{|c|}{ Subtotal (I-squared $=48.6 \%, p=0.163$ ) }} \\
\hline & & \\
\hline \multicolumn{3}{|l|}{ Fatigue } \\
\hline Mateos (2019) & $0.05(0.00,0.81)$ & 77.47 \\
\hline Usmani (2019) & $1.62(0.39,6.66)$ & 22.53 \\
\hline Subtotal $(I-$ squared $=83.1 \%, p=0.015$ & $0.40(0.15,1.08)$ & 100.00 \\
\hline Overall $(I-$ squared $=16.6 \%, p=0.272)$ & $1.03(0.96,1.11)$ & . \\
\hline .00285 & 51 & \\
\hline
\end{tabular}

Fig. 8 Forest plots of the pooled RRs for the ORR, disease control, and grade 3 or higher hematological (including neutropenia, and anemia) and non-hematological (including pneumonia, diarrhea, and fatigue) adverse events of the patients with MM in the MAbs targeting PD-1/PD-L1 group versus control group. The RRs for the ORR and disease control $>1$ favour the MAb group. The RRs for the incidence of adverse events $<1$ favour the MAb group. The size of the blocks or diamonds represents the weight of the fixed effects model in the meta-analysis

Table 3 The indirect-comparison results of efficacy and safety of MAbs targeting CD38, SLAMF7 and PD-1/PD-L1 groups

\begin{tabular}{|c|c|c|c|}
\hline Outcomes & Antibodies targeting CD38 vs SLAMF7 & $\begin{array}{l}\text { Antibodies targeting } \\
\text { CD38 vs PD-1/PD-L1 }\end{array}$ & $\begin{array}{l}\text { Antibodies targeting } \\
\text { SLAMF7 vs PD-1/PD-L1 }\end{array}$ \\
\hline PFR - HR(95Cl) & $0.662(0.543,0.806)$ & $0.317(0.221,0.454)$ & $0.479(0.328,0.699)$ \\
\hline OS - HR(95Cl) & $0.812(0.584,1.127)$ & NA & NA \\
\hline ORR - RR(95Cl) & $0.976(0.763,1.248)$ & $1.247(1.035,1.503)$ & $1.278(0.968,1.688)$ \\
\hline CR or better-RR(95Cl) & $2.253(1.284,3.955)$ & NA & NA \\
\hline VGPR or better-RR(95Cl) & $1.304(0.956,1.778)$ & NA & NA \\
\hline VGPR - RR(95CI) & $0.993(0.671,1.468)$ & NA & NA \\
\hline PR- RR(95Cl) & $1.522(0.876,2.642)$ & NA & NA \\
\hline$S D-\operatorname{RR}(95 \mathrm{Cl})$ & $0.636(0.368,1.099)$ & NA & NA \\
\hline Neutropenia - RR(95Cl) & $1.818(1.41,2.344)$ & $1.207(0.94,1.55)$ & $0.664(0.515,0.855)$ \\
\hline Anemia-RR(95Cl) & $0.932(0.656,1.323)$ & $0.566(0.332,0.963)$ & $0.607(0.346,1.064)$ \\
\hline Thrombocytopenia -RR(95Cl) & $1.186(0.83,1.694)$ & NA & NA \\
\hline Lymphopenia -RR(95Cl) & $1.043(0.753,1.444)$ & NA & NA \\
\hline Pneumonia-RR(95Cl) & $1.144(0.72,1.817)$ & $1.325(0.725,2.419)$ & $1.158(0.58,2.311)$ \\
\hline Diarrhea-RR(95Cl) & $1.00(0.497,2.014)$ & $0.446(0.102,1.956)$ & $0.446(0.095,2.105)$ \\
\hline Fatigue-RR(95Cl) & $1.681(0.903,3.13)$ & $5.00(1.717,14.56)$ & $2.975(0.998,8.867)$ \\
\hline
\end{tabular}

Abbreviations: PFS progression-free survival, $O S$ overall survival, ORR overall response rate, $C R$ complete response, VGPR very good partial response, $P R$ partial response, $S D$ stable disease, $H R$ hazard ratio, $R R$ relative risk, $N A$ not available 


\section{Conclusions}

In general, the MAbs targeting CD38 in combination with bortezomib/immunomodulators plus dexamethasone/prednisone showed a significant therapeutic value in patients with MM. Although the treatment with the MAbs targeting SLAMF7 group was not as effective as that with the MAbs targeting CD38 group, it had a lower incidence of adverse events and may be more suitable for patients with poor drug tolerance. The therapeutic effect of the MAbs targeting PD-1/PD-L1 group was poor and the incidence of adverse events was not reduced or was even higher in comparison with the control or the other two groups, offering a limited therapeutic value to patients with MM. We found that different MAbs directing to different targets in combination with other agents had different effects; therefore, this study could provide a resource for clinicians when selecting an antibody to combine with other drugs for the treatment of MM.

\section{Abbreviations}

PFS: Progression-free survival; OS: Overall survival; ORR: Overall response rate; CR: Complete response; VGPR: Very good partial response; PR: Partial response; SD: Stable disease; HR: Hazard ratio; RR: Relative risk; MM: Multiple myeloma

\section{Supplementary Information}

The online version contains supplementary material available at https://doi. org/10.1186/s12885-021-08588-9.

Additional file 1: Table 1. Characteristics of the patients at baseline Table 2. Characteristics of the patients at baseline.

\section{Acknowledgements}

Not applicable.

\section{Authors' contributions}

WY and YPG contributed to the study conception and design. Material preparation, data collection and analysis were performed by $W Y, X W, X Z$, $X Y L$, JLD and YPG. The first draft of the manuscript was written by WY, and all authors commented on previous versions of the manuscript. All authors read and approved the final manuscript.

\section{Funding}

The work was supported by the Foundation of the Science and Technology Department of Sichuan Province (NO.2019YFS0026).

\section{Availability of data and materials}

Not applicable.

\section{Declarations}

Ethics approval and consent to participate

Not applicable.

Consent for publication

Not applicable.

\section{Competing interests}

The authors declare that they have no competing interests.
Received: 10 November 2020 Accepted: 5 July 2021

Published online: 06 September 2021

\section{References}

1. Morandi F, Horenstein AL, Costa F, Giuliani N, Pistoia V, Malavasi F. CD38: a target for immunotherapeutic approaches in multiple myeloma. Front Immunol. 2018;9:2722. https://doi.org/10.3389/fimmu.2018.02722.

2. Chini EN, Chini C, Espindola NJ, de Oliveira GC, van Schooten W. The pharmacology of CD38/NADase: an emerging target in Cancer and diseases of aging. Trends Pharmacol Sci. 2018;39(4):424-36. https://doi.org/10.1016/j. tips.2018.02.001.

3. van de Donk N, Usmani SZ. CD38 antibodies in multiple myeloma: mechanisms of action and modes of resistance. Front Immunol. 2018;9: 2134. https://doi.org/10.3389/fimmu.2018.02134

4. Malaer JD, Mathew PA. CS1 (SLAMF7, CD319) is an effective immunotherapeutic target for multiple myeloma. Am J Cancer Res. 2017; 7(8):1637-41.

5. Malaer JD, Marrufo AM, Mathew PA. 2 B4 (CD244, SLAMF4) and CS1 (CD319, SLAMF7) in systemic lupus erythematosus and cancer. Clin Immunol. 2019; 204:50-6. https://doi.org/10.1016/j.clim.2018.10.009.

6. Chen J, Zhong MC, Guo H, Davidson D, Mishel S, Lu Y, et al. SLAMF7 is critical for phagocytosis of haematopoietic tumour cells via mac-1 integrin. NATURE. 2017;544(7651):493-7. https://doi.org/10.1038/nature22076.

7. Pazina T, James AM, MacFarlane AT, Bezman NA, Henning KA, Bee C, et al. The anti-SLAMF7 antibody elotuzumab mediates NK cell activation through both CD16-dependent and -independent mechanisms. Oncoimmunology. 2017;6(9):e1339853. https://doi.org/10.1080/2162402X.2017.1339853.

8. Ishibashi M, Soeda S, Sasaki M, Handa H, Imai Y, Tanaka N, et al. Clinical impact of serum soluble SLAMF7 in multiple myeloma. Oncotarget. 2018; 9(78):34784-93. https://doi.org/10.18632/oncotarget.26196.

9. Rosenblatt J, Avigan D. Targeting the PD-1/PD-L1 axis in multiple myeloma: a dream or a reality? BLOOD. 2017;129(3):275-9. https://doi.org/10.1182/ blood-2016-08-731885.

10. Oliva S, Troia R, D'Agostino M, Boccadoro M, Gay F. Promises and pitfalls in the use of PD-1/PD-L1 inhibitors in multiple myeloma. Front Immunol. 2018; 9:2749. https://doi.org/10.3389/fimmu.2018.02749.

11. Lesokhin AM, Bal S, Badros AZ. Lessons learned from checkpoint blockade targeting PD-1 in multiple myeloma. Cancer Immunol Res. 2019;7(8):1224-9. https://doi.org/10.1158/2326-6066.CIR-19-0148.

12. Zheng $Y$, Shen $H$, Xu L, Feng J, Tang H, Zhang N, et al. Monoclonal antibodies versus histone deacetylase inhibitors in combination with Bortezomib or Lenalidomide plus dexamethasone for the treatment of relapsed or refractory multiple myeloma: an indirect-comparison Metaanalysis of randomized controlled trials. J Immunol Res. 2018;2018:1-20.

13. Kodama S, Fujihara K, Horikawa C, Harada M, Ishiguro H, Kaneko M, et al. Network meta-analysis of the relative efficacy of bariatric surgeries for diabetes remission. Obes Rev. 2018;19(12):1621-9. https://doi.org/10.1111/obr.12751.

14. Mateos MV, Cavo M, Blade J, Dimopoulos MA, Suzuki K, Jakubowiak A, et al. Overall survival with daratumumab, bortezomib, melphalan, and prednisone in newly diagnosed multiple myeloma (ALCYONE): a randomised, openlabel, phase 3 trial. LANCET. 2020;395(10218):132-41. https://doi.org/10.101 6/S0140-6736(19)32956-3.

15. Spencer A, Lentzsch S, Weisel K, Avet-Loiseau H, Mark TM, Spicka I, et al. Daratumumab plus bortezomib and dexamethasone versus bortezomib and dexamethasone in relapsed or refractory multiple myeloma: updated analysis of CASTOR. Haematologica. 2018;103:2079-87.

16. Dimopoulos MA, San-Miguel J, Belch A, White D, Benboubker L, Cook G, et al. Daratumumab plus lenalidomide and dexamethasone versus lenalidomide and dexamethasone in relapsed or refractory multiple myeloma: updated analysis of POLLUX. Haematologica. 2018;103:2088-96.

17. Dimopoulos MA, Lonial S, Betts KA, Chen C, Zichlin ML, Brun A, et al. Elotuzumab plus lenalidomide and dexamethasone in relapsed/refractory multiple myeloma: extended 4-year follow-up and analysis of relative progression-free survival from the randomized ELOQUENT-2 trial. Cancer Am Cancer Soc. 2018;124:4032-43.

18. Attal M, Richardson PG, Rajkumar SV, San-Miguel J, Beksac M, Spicka I, et al. Isatuximab plus pomalidomide and low-dose dexamethasone versus pomalidomide and low-dose dexamethasone in patients with relapsed and refractory multiple myeloma (ICARIA-MM): a randomised, multicentre, openlabel, phase 3 study. Lancet. 2019:394(10214):2096-107. https://doi.org/10.1 016/S0140-6736(19)32556-5. 
19. Moreau P, Attal M, Hulin C, Arnulf B, Belhadj K, Benboubker L, et al. Bortezomib, thalidomide, and dexamethasone with or without daratumumab before and after autologous stem-cell transplantation for newly diagnosed multiple myeloma (CASSIOPEIA): a randomised, openlabel, phase 3 study. Lancet. 2019;394:29-38.

20. Facon T, Kumar S, Plesner T, Orlowski RZ, Moreau P, Bahlis N, et al. Daratumumab plus Lenalidomide and dexamethasone for untreated myeloma. N Engl J Med. 2019;380(22):2104-15. https://doi.org/10.1056/ NEJMoa1817249.

21. Mateos MV, Dimopoulos MA, Cavo M, Suzuki K, Jakubowiak A, Knop S, et al. Daratumumab plus Bortezomib, Melphalan, and prednisone for untreated myeloma. N Engl J Med. 2018;378(6):518-28. https://doi.org/10.1056/ NEJMoa1714678.

22. Dimopoulos MA, Oriol A, Nahi H, San-Miguel J, Bahlis NJ, Usmani SZ, et al. Daratumumab, Lenalidomide, and dexamethasone for multiple myeloma. $\mathrm{N}$ Engl J Med. 2016;375(14):1319-31. https://doi.org/10.1056/NEJMoa1607751.

23. Palumbo A, Chanan-Khan A, Weisel K, Nooka AK, Masszi T, Beksac M, et al. Daratumumab, Bortezomib, and dexamethasone for multiple myeloma. N Engl J Med. 2016;375(8):754-66. https://doi.org/10.1056/NEJMoa1606038.

24. Lonial S, Dimopoulos M, Palumbo A, White D, Grosicki S, Spicka I, et al. Elotuzumab therapy for relapsed or refractory multiple myeloma. N Engl J Med. 2015:373(7):621-31. https://doi.org/10.1056/NEJMoa1505654.

25. Jakubowiak A, Offidani M, Pegourie B, De La Rubia J, Garderet L, Laribi K, et al. Randomized phase 2 study: elotuzumab plus bortezomib/dexamethasone vs bortezomib/dexamethasone for relapsed/refractory MM. BLOOD. 2016;127(23): 2833-40. https://doi.org/10.1182/blood-2016-01-694604.

26. Dimopoulos MA, Dytfeld D, Grosicki S, Moreau P, Takezako N, Hori M, et al. Elotuzumab plus Pomalidomide and dexamethasone for multiple myeloma. N Engl J Med. 2018;379(19):1811-22. https:/doi.org/10.1056/NEJMoa1805762.

27. Usmani SZ, Schjesvold F, Oriol A, Karlin L, Cavo M, Rifkin RM, et al. Pembrolizumab plus lenalidomide and dexamethasone for patients with treatment-naive multiple myeloma (KEYNOTE-185): a randomised, openlabel, phase 3 trial. Lancet Haematol. 2019;6(9):e448-58. https://doi.org/10.1 016/S2352-3026(19)30109-7.

28. Mateos MV, Blacklock H, Schjesvold F, Oriol A, Simpson D, George A, et al, Pembrolizumab plus pomalidomide and dexamethasone for patients with relapsed or refractory multiple myeloma (KEYNOTE-183): a randomised, open-label, phase 3 trial. Lancet Haematol. 2019;6(9):e459-69. https://doi. org/10.1016/S2352-3026(19)30110-3

29. Bonello F, D'Agostino M, Moscvin M, Cerrato C, Boccadoro M, Gay F. CD38 as an immunotherapeutic target in multiple myeloma. Expert Opin Biol Ther. 2018;18(12):1209-21. https://doi.org/10.1080/14712598.2018.1544240.

30. Yang WC, Lin SF. Mechanisms of drug resistance in relapse and refractory multiple myeloma. Biomed Res Int. 2015;2015:341430.

31. van de Donk N, Richardson PG, Malavasi F. CD38 antibodies in multiple myeloma: back to the future. BLOOD. 2018;131(1):13-29. https://doi.org/1 0.1182/blood-2017-06-740944.

32. Korkmaz S, Erdem S, Akay E, Tasdemir EA, Karaman H, Keklik M. Do PD-1 and PD-L2 expressions have prognostic impact in hematologic malignancies? Turk J Med Sci. 2019:49(1):265-71. https://doi.org/10.3906/sag-1706-194.

33. Jelinek T, Paiva B, Hajek R. Update on PD-1/PD-L1 inhibitors in multiple myeloma. Front Immunol. 2018;9:2431. https://doi.org/10.3389/fimmu.2018.02431.

34. Jelinek T, Mihalyova J, Kascak M, Duras J, Hajek R. PD-1/PD-L1 inhibitors in haematological malignancies: update 2017. Immunology. 2017;152(3):35771. https://doi.org/10.1111/imm.12788.

\section{Publisher's Note}

Springer Nature remains neutral with regard to jurisdictional claims in published maps and institutional affiliations.

Ready to submit your research? Choose BMC and benefit from:

- fast, convenient online submission

- thorough peer review by experienced researchers in your field

- rapid publication on acceptance

- support for research data, including large and complex data types

- gold Open Access which fosters wider collaboration and increased citations

- maximum visibility for your research: over $100 \mathrm{M}$ website views per year

At $\mathrm{BMC}$, research is always in progress.

Learn more biomedcentral.com/submissions 